\title{
Special Considerations in Esthesioneuroblastoma of Sphenoclival Region
}

\author{
Shawn T Joseph, Aliasgar V Moiyadi, Deepa R Nair, Prashant V Pawar, Prathamesh S Pai
}

\begin{abstract}
Ectopic localization of esthesioneuroblastoma is very rare. The differential diagnosis arising due to this would not only challenge a clinician's experience and knowledge in pathology, interpretation of imaging and decision making but also test his fine skills in skull base surgery. Here, we present a case of esthesioneuroblastoms located in the sphenoclival area which challenged us with its rare presentation, histological and radiological differential diagnosis and demanding surgery. We have put an effort to discuss briefly the pathogenesis and management of esthesioneuroblastoma based on a wide text and internet data-based search. Our experience makes us conclude that the proper clinical and tissue diagnosis of sphenoclival masses are of utmost importance as the management options are wide and varied in each of them. A multidisciplinary team approach should be adopted in treating these tumors as the histological and radiological interpretation is as difficult as the complicated surgical anatomy of this area. Endoscopic approach can be successfully used in the excision of ectopic esthesioneuroblastoma located in the sphenoclival region.
\end{abstract}

Keywords: Esthesioneuroblastoma, Skull base neoplasm, Sphenoid sinus, Olfactory neuroblastoma, Nose neoplasms, Carotid artery.

How to cite this article: Joseph ST, Moiyadi AV, Nair DR, Pawar PV, Pai PS. Special Considerations in Esthesioneuroblastoma of Sphenoclival Region. Int J Head and Neck Surg 2012;3(3):158-162.

\section{Source of support: Nil}

Conflict of interest: None declared

\section{INTRODUCTION}

Masses arising in the sphenoclival region can mimic each other clinically in a number of ways. The variability in the management options of the sphenoclival masses calls for utmost care in the clinical evaluation and diagnosis of each of them. Here, we present an uncommon case of esthesioneuroblastoma located ectopically in the sphenoclival region. It was the rarity of the condition, varying management options and special surgical challenges that prompted us to report this case.

\section{CASE REPORT}

A 44-year-old female presented with a complaint of gradually increasing pain on the right side of face for the past 2 years. There was no history of any other nasal or ocular complaints. On diagnostic nasal endoscopy, a submucosal swelling was seen in the posterior part of nasal septum. Magnetic resonance imaging (MRI) scan of the paranasal sinuses showed a mass lesion involving the clivus and sphenoid sinus with extension into the nasopharynx and posterior ethmoid air cells on both sides. The lesion appeared hypointense on T1-weighted images and heterogeneously hyperintense on T2-weighted images with inhomogeneous postcontrast enhancement. This was involving the cavernous sinuses on both sides with encasement of the cavernous portion of both internal carotid arteries, which were patent. The brain parenchyma and pituitary were normal (Figs 1 to 3). Differential diagnoses on imaging were chordoma, carcinoma of nasopharynx or carcinoma of sphenoid sinus with involvement of the clivus. Endoscopic biopsy report was favoring a neuroendocrine

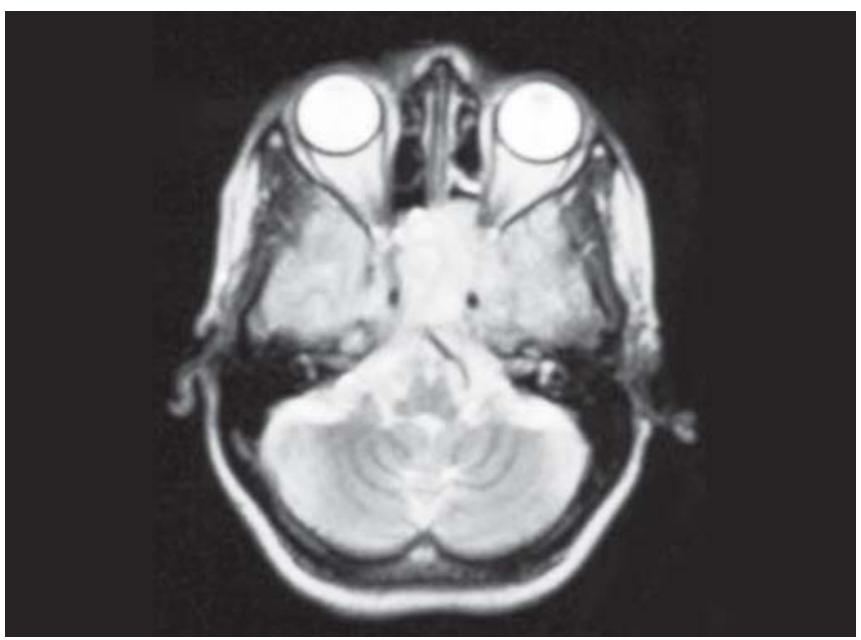

Fig. 1: MRI showing enhancing mass in the spheno-clival region close to the internal carotid artery and orbital apex (preoperative)

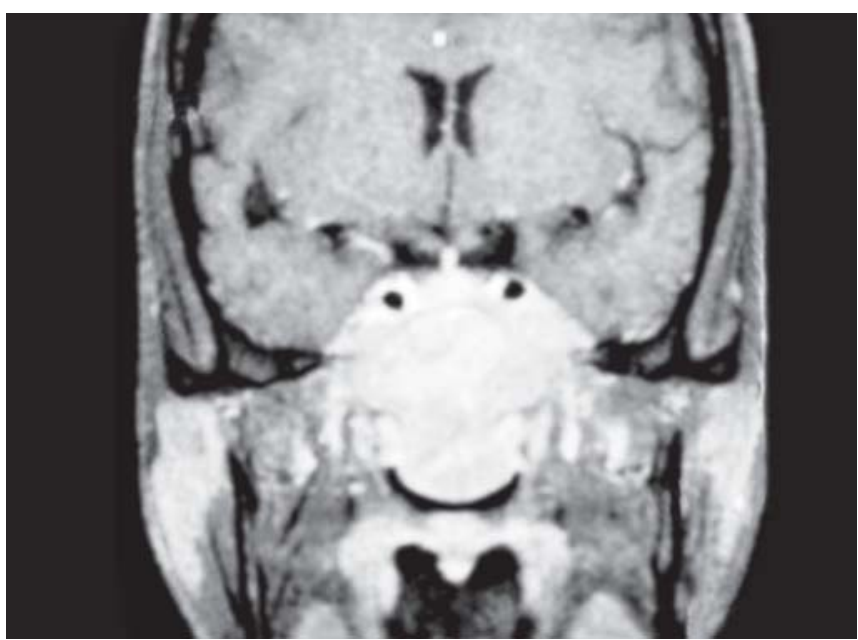

Fig. 2: Coronal T1-weighted MRI of spheno-clival mass close to the internal carotid arteries (preoperative) 


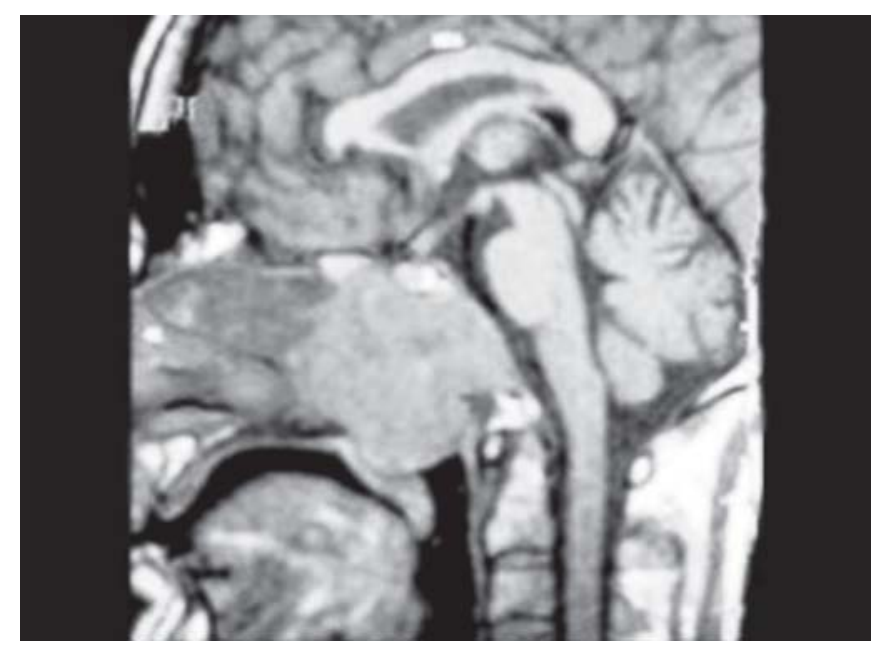

Fig. 3: Sagittal T1-weighted MRI of spheno-clival mass (preoperative)

tumor with a differential of invasive pituitary adenoma presenting as a clivus tumor.

After considering the various possibilities it was decided to go for an endonasal endoscopic resection of the sphenoclival mass. During surgery the tumor was found to be easily separable from lateral sphenoid wall. Care was taken during instrumentation to avoid injury to the internal carotid artery. Lateral walls of sphenoid were seen eroded by tumor near the lower part. Tumor was excised piecemeal, going laterally up to the posterior wall of maxilla. Bilateral internal carotid arteries were seen exposed in the lateral wall of sphenoid, the bony covering having been eroded by the tumor. All anatomic landmarks within the sphenoid sinus were identified. Both optic nerves were found to be uninvolved by the disease. Sella was seen thinned out, but bone was present. Pituitary fossa was normal.

On immunohistochemistry, tumor cells were found to be positive for chromogranin and synaptophysin and negative for cytokeratin, leukocyte common antigen and epithelial membrane antigen. Features were of a neuroendocrine tumor, consistent with an esthesioneuroblastoma of sphenoclival region eroding the bone. Postoperative radiation therapy was administered to the patient. Three years after surgery, the patient is free of disease. Postoperative MRI scan after 2.5 years shows post- treatment changes involving the basisphenoid, clivus and both the greater wings of sphenoid (Figs 4 to 6). No associated intracranial or extracranial soft tissue mass was observed.

\section{DISCUSSION}

\section{Background}

Esthesioneuroblastoma is an uncommon malignancy derived from olfactory neuroepithelium. This was first reported in 1924 by Berger and Luc, ${ }^{1}$ who described an 'esthesioneuroepitheliome olfactif'. The olfactory epithlelium occupies

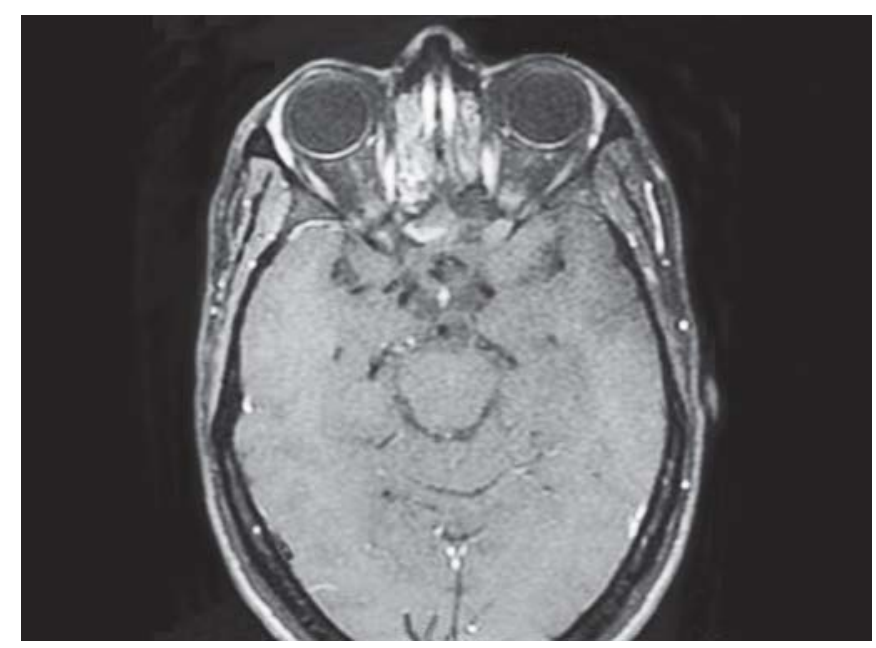

Fig. 4: MRI scan showing axial view 1 year after surgery (postoperative)

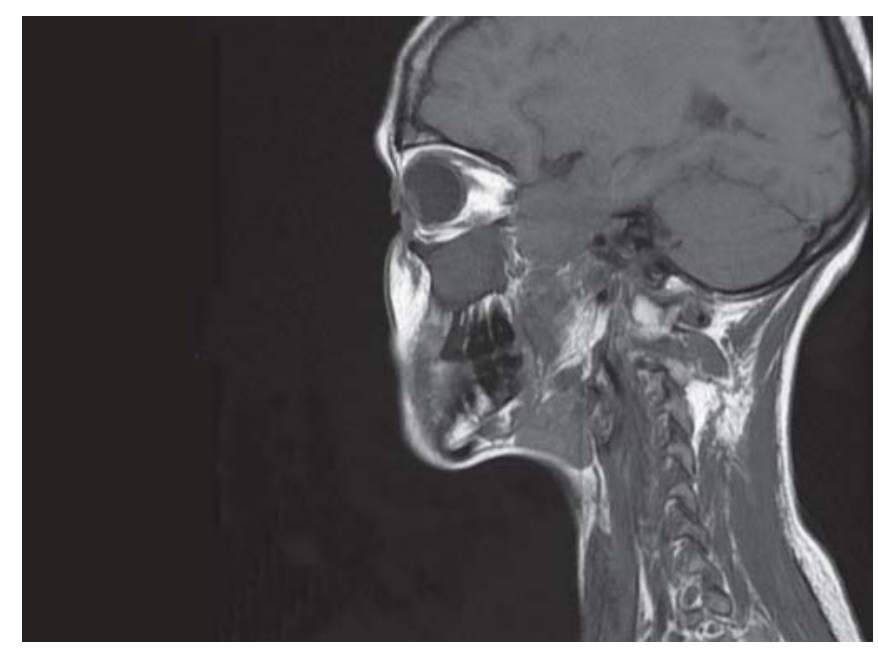

Fig. 5: Sagittal view of the spheno-clival region showing postoperative status

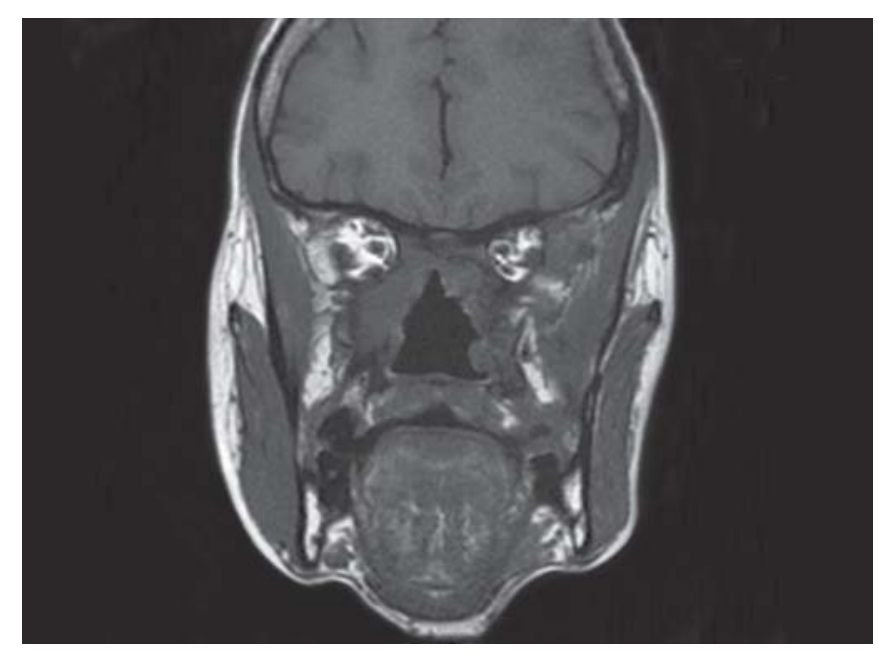

Fig. 6: Coronal view of the spheno-clival region showing postoperative status

the superior nasal fossa, covering the cribriform plate, superior nasal septum and medial aspect of the supreme and superior turbinates. 


\section{Pathophysiology}

Several theories have been proposed to explain the origin of esthesioneuroblastoma. The multipotential basal cell is thought to be the cell of origin of esthesioneuroblastoma by some authors. But when this tumor arises from areas other than the cribriform niche, as in the above case, it becomes important to check the embryological distribution of olfactory neuroepithelium as well as other possibilities. The development of an esthesioneuroblastoma outside to the region in which olfactory epithelium exists is extremely rare. $^{2}$

Jakumeit in $1971^{3}$ proposed the theory of nervus terminalis to explain the origin of esthesioneuroblastoma. Cells of the terminal system, diffusely scattered, persisting beyond fetal life may provide an origin for esthesioneuroblastoma in these locations. ${ }^{4}$ Zappia et $\mathrm{al}^{5}$ in 1992 described a model for blocked migration of olfactory placode neuronal cells to explain the origin of esthesioneuroblastoma in a case of Kallmann syndrome. This was due to deletion of a gene encoding a protein homologous to the neural cell adhesion molecule N-CAM. ${ }^{6}$

To date, no certain genetic factor has been identified that can accurately assist in the diagnosis or predict prognosis. Recently, array comparative genomic hybridization was applied to the analysis of esthesioneuroblastoma. ${ }^{7}$ The human achaete-scute homologue 1 (HASH 1) - gene is involved in olfactory neuronal differentiation and is expressed in immature olfactory cells. ${ }^{8}$ Therefore, it could be useful in distinguishing esthesioneuroblastoma from other poorly differentiated small blue cell tumors.

\section{Clinical Presentation}

An eshthesioneuroblastoma arising in the sphenoclival region can lead to diagnostic delay, as the differential diagnoses can be hard to rule out. Regarding a lesion involving the sphenoid area, the differential diagnosis should include primary sphenoid sinus carcinoma, meningioma, nasopharyngeal carcinoma, clival chordoma and pituitary adenoma. ${ }^{9}$ The incidence of esthesioneuroblastoma follows a bimodal distribution with peaks from 10 to 30 and 50 to 70 years of age. Nasal and ocular symptoms which occur in esthesioneuroblastoma may not be the initial symptoms if the localization of esthesioneuroblastoma is ectopic, like the sphenoclival region. Hormonal abnormalities and visual field deficits and 4th, 6th and/or 5th cranial nerve involvement were the clinical presentations in previously reported cases of estheioneuroblastomas around the sellar region. ${ }^{10}$ Cerebrospinal fluid rhinorrhea with meningitis has been reported as the clinical presentation in one of the cases. ${ }^{11}$ None of these clinical features will actually give a definite clue to the diagnosis of esthesioneuroblastoma as the other differential diagnosis in this area can also have similar clinical presentations. Regional and distant metastases occur in 14 to $38 \%$ of patients of esthesioneuroblastoma, most commonly to cervical lymph nodes and bones. ${ }^{12}$ This is a feature which can occur in ectopically located esthesioneuroblastoma as well.

\section{Imaging}

In deep seated skull base lesions where biopsy is difficult and invasive, such as these, imaging is an important modality for diagnosis. On computed tomographic (CT) scan, the clival chordoma is characterized by both bone destruction and a soft tissue mass without sclerotic margins. Calcifications are frequently present and tend to be fairly large. The MR appearance is quite variable. Pituitary adenoma can be very large and destructive, extending inferiorly to the sphenoid sinus and nasopharynx and posteriorly to involve the clivus. Esthesioneuroblastoma, on CT scan, often appears as a homogeneous, contrast enhancing mass, occasionally with calcified or cystic areas in larger lesions. ${ }^{16}$ On MRI, this tumor commonly results in intermediate signal intensity in both $\mathrm{T} 1$ and $\mathrm{T} 2$ images. Chirico et $\mathrm{al}^{9}$ reported the first case of a primary esthesioneuroblastoma of the sphenoid sinus imaged with MRI and showed that, although this entity is rare, the imaging characteristics are consistent. In our case the imaging was equivocal and all these were considered as differentials.

\section{Staging}

Various staging systems exist for esthesioneuroblastoma. The most commonly followed ones include Kadish classification and the classification system proposed by Dulgerov and Calcaterra. ${ }^{13}$ The Kadish system puts all tumors beyond paranasal sinuses in one stage. Dulgerov and Calcaterra system stages tumors with extension to the orbit or anterior cranial fossa as T3, and those with involvement of the brain as T4. This system seems to allow better clarity in treatment planning because the management for T3 and T4 tumors may vary. Even for T2 and T3 tumors, the surgical approaches can vary. From a surgical point of view this system seems to offer the liberty to place the ectopic tumors also in the same stages, though the staging may fail to give information regarding the extent of an ectopic tumor. Histopathological evaluation of esthesioneuroblastoma by Hyam's grading is also important in predicting the behavior of the tumor, as described by many authors. ${ }^{13,14}$ 


\section{Management}

Due to the rarity of esthesioneuroblastoma, the optimal management method for patients with this disease is poorly defined. Over the years, primary surgery, primary radiotherapy, and combined surgery and radiotherapy have been employed against esthesioneuroblastoma. Adjuvant chemotherapy has been tried with some success for recurrent, unresectable and metastatic esthesioneuroblastoma.

Chemotherapy has generally not been the first choice for resectable esthesioneuroblastoma, but a multitude of drugs have achieved cytoreduction in advanced cases in some studies. Polonowski et $\mathrm{al}^{15}$ from France reported a case of complete regression of recurrent esthesioneuroblastoma using a regimen of cisplatin and 5-FU. More study is needed regarding the efficacy of chemotherapy in esthesioneuroblastoma.

The therapeutic debate in esthesioneuroblastoma centers on primary surgery with radiotherapy held in reserve for recurrences vs combination therapy. Majority of institutions consider surgical resection with adjuvant radiotherapy as the management of choice. ${ }^{13}$ Elkon et al $^{16}$ in 1979 reviewed 97 cases and concluded that both treatment options, as well as primary radiotherapy, were equally effective in treating Kadish stages A and B. They found combination therapy more effective in stage $C$ patients. Dulguerov et al ${ }^{13}$ advocate combination therapy in all cases, with radiotherapy administered postoperatively. Of 26 patients reviewed, they document 92\% disease free tumor control in those treated with a combination protocol vs $14 \%$ control with surgery alone and 40\% control with radiotherapy alone. Levine et $\mathrm{al}^{17}$ likewise advocate combination therapy, with preoperative radiotherapy, in all stage A and B cases of esthesioneuroblastoma. They employ pre- and postoperative chemotherapy in stage $\mathrm{C}$ cases. Biller et $\mathrm{al}^{18}$ maintain that an adequate surgical resection yields results superior to combination therapy, and they hold radiotherapy in reserve for recurrences, unresectable tumors and cases of incomplete excision. In a series of Mayo Clinic, ${ }^{14}$ the incidence of recurrence was reduced by postoperative radiotherapy. Chemotherapy had been used mainly as an adjunct in advanced cases or in combination with radiotherapy. Surgery plus either pre- or postoperative chemotherapy and postoperatve radiotherapy appears to be of benefit in advanced cases.

Multimodality treatments are the most frequently advocated interventions, and literature shows that craniofacial resection is the most common therapy. Endoscopic skull base surgery has come up in a big way that lesions located in the trajectory of the endoscope may have an equal or better surgical clearance with significantly lesser morbidity if resected endoscopically. ${ }^{19}$ Endoscopic resection scores over radical surgical approaches in many aspects like better visualization of sites that are otherwise difficult to visualize, such as the paranasal sinuses, cribriform plate, lateral recesses of sphenoid sinus, lesser morbidity, function preservation, cosmesis and lesser hospital stay. If available, the computer-assisted surgery has proven to be a valuable tool in organizing one's surgical planning at the base of the skull.

Sphenoclival lesions lend themselves to a transnasal endoscopic access. Though there are consistent landmarks in the endoscopic endonasal anatomy, experience in skull base is important as the disease may modify the anatomy in these areas and mislead the surgeon during endoscopic resection. A thorough knowledge of the endoscopic and radiologic anatomy of this region is an absolute must while operating in this area. Anatomic landmarks within the sphenoid sinus like planum sphenoidale, sella, clival recess, optic canal, medial and lateral carotico-optic recesses and the carotid canal should be identified. Any form of aggressive instrumentation should be avoided to prevent damage to internal carotid artery. Possibilities like a dehiscent canal, disease eroding the canal and variable pneumatization of sphenoid sinus should be taken care of. The surgeon should have a thorough knowledge of the endoscopic approaches of the petroclival area. During dissection near the clivus, utmost care should be exercised to avoid injury to the basilar venous plexus which lies between the endosteal and visceral layers of the dura on the inner surface of the clivus. Thorough inspection of the area using an angled endoscope is essential to clear possible tumor remnants among the critical anatomical structures in this area. Inspection should be done to identify dural tears which require meticulous repair, if present. A multidisciplinary team consisting of otorhinolaryngologist and neurosurgeon is an absolute necessity while dealing with tumors in the sphenoclival area. ${ }^{20}$ Outcome for patients who have undergone endoscopic surgical treatment of esthesioneuroblastoma needs to be studied in larger series with longer follow-up periods.

\section{CONCLUSION}

The proper clinical and tissue diagnosis of sphenoclival masses are of utmost importance as the management options are wide and variable in each of them. Ability to interpret the fine details in imaging, expertise and experience in tissue diagnosis are required to fetch the correct diagnosis and predict the outcome. Endoscopic approach can be successfully used in the excision of ectopic esthesioneuroblastoma located in the sphenoclival region. A multidisciplinary team approach is essential to get the best results. 


\section{REFERENCES}

1. Berger L, Luc G, Richard D. L’esthésioneuroépithéliome olfactif. Bull Assoc Franç Étude Cancer 1924;13:410-21.

2. Mc CL, Harris HE. Neurogenic tumors of the nasal fossa. J Am Med Assoc 1955;157(4):318-21.

3. Jakumeit HD. Neuroblastoma of the olfactory nerve. Acta Neurochir 1971;25:99-108.

4. Wirsing Weichmann AF, Eisthen HL. What defines the nervus terminalis? Neurochemical development and anatomical criteria. Prog Brain Res 2002;141:45-55.

5. Zappia JJ, Bradford CR, Winter P, McClatchey KD. Olfactory neuroblastoma associated with Kallmann syndrome. J Otolaryngol 1992;21:16-19.

6. Schwanzel-Fukuda M, Pfaff DW. LHRH - expressing cells do not migrate normally in an inherited hypogonadal (Kallmann) syndrome. Brain Res Mol Brain Res 1989;6:311-26.

7. Guled M, Myllykangas S, Freierson HF Jr, Mills SE, Knuutila $\mathrm{S}$, Stelow EB. Array comparative geomic hybridization analysis of olfactory neuroblastoma. Mod Pathol 2008;21(6):770-78.

8. Carney ME, O’ Reilly RC, Sholevar B. Expression of the human Achaete-scute 1 gene in olfactory neuroblastoma (esthesioneuroblastoma). J Neurooncol 1995;26(1):35-43.

9. Chirico G, Pergolizzi S, Mazziotti S. Primary sphenoid esthesioneuroblastoma studied with MR. Clin Imaging 2003;27(1): 38-40.

10. Morris L, Govindraj S, Genden EM. Primary sphenoid sinus esthesioneuroblastoma. Am J Otol aryngol 2004;25(5):350-53.

11. Jiann-Her L, Dong-Han T, Yung-Hsiao C. A primary sellar esthesioneuroblastoma with unusual presentations: A case report and reviews of literatures. Pituitary 2009;12:70-75.

12. Som PM. Sinonasal cavities: Inflammatory disease, tumors, fractures and postoperative findings. Head and Neck Imaging St Lous: Mosby 1996;126-318.

13. Dulguerov P, Calcaterra T. Esthesioneuroblastoma: The UCLA experience 1970-1990. Laryngoscope 1992;102(8):843-49.

14. McElroy EA Jr, Buckner JC, Lewis JE. Chemotherapy for advanced esthesioneuroblastoma: The Mayo Clinic experience. Neurosurgery 1998;42(5):1023-27.

15. Polonowski JM, Brasnu D, Roux FX, Bassot V. Esthesioneuroblastoma: Complete tumor response after induction chemotherapy. Ear Nose Throat J 1990;69:743-46.
16. Elkon D, Hightower SI, Lim ML, Cantrell RW, Constable WC. Esthesioneuroblastoma. Cancer 1979;44:1087-94.

17. Levine PA, McLean WC, Cantrell RW. Esthesioneuroblastoma: The University of Virginia experience 1960-1985. Laryngoscope 1986;96(7):742-46.

18. Biller HF, Lawson W, Sachdev VP, Som P. Esthesioneuroblastoma: Surgical treatment without radiation. Laryngoscope 1990;100:1199-201.

19. Carrau RL, Kassam AB, Snyderman CH, Duvvuri U, Mintz A, Gardner P. Endoscopic transnasal anterior skull base resection for the treatment of sinonasal malignancies. Operative Techniques Otolaryngol Head Neck Surg 2006;17:102-10.

20. Zanation AM, Snyderman CH, Carrau RL, Gardner PA, Prevedello DM, Kassam AB. Endoscopc endonasal surgery for petrous apex lesions. Laryngoscope 2009;119:19-25.

\section{ABOUT THE AUTHORS}

\section{Shawn T Joseph}

Senior Registrar, Department of Head and Neck Surgery, Tata Memorial Hospital, Mumbai, Maharashtra, India

\section{Aliasgar V Moiyadi}

Associate Professor, Department of Neurosurgery, Tata Memorial Hospital, Mumbai, Maharashtra, India

\section{Deepa R Nair}

Assistant Professor, Department of Head and Neck Surgery, Tata Memorial Hospital, Mumbai, Maharashtra, India

\section{Prashant V Pawar}

Fellow, Department of Head and Neck Surgery, Tata Memorial Hospital Mumbai, Maharashtra, India

\section{Prathamesh S Pai (Corresponding Author)}

Associate Professor, Department of Head and Neck Surgery, Tata Memorial Hospital, Mumbai, Maharashtra, India, e-mail: drpspai@gmail.com 